\title{
Supplemental Material for: Pre-Columbian Lead Pollution from Native American Galena Processing and Land Use in the Midcontinental United States
}

${ }^{1}$ Broxton W. Bird, ${ }^{2}$ Jeremy J. Wilson, ${ }^{3,4}$ Jaime H. Escobar, ${ }^{5}$ George Kamenov, ${ }^{1}$ Harvie J. Pollard, and ${ }^{2} \mathrm{G}$. William Monaghan

${ }^{1}$ Department of Earth Sciences, Indiana University-Purdue University, Indianapolis, IN 46202

${ }^{2}$ Department of Anthropology, Indiana University-Purdue University, Indianapolis, IN 46202

${ }^{3}$ Universidad del Norte, Barranquilla, Colombia

${ }^{4}$ Smithsonian Tropical Research Institute, Panama City, Panama

${ }^{5}$ Department of Geological Sciences, University of Florida, Gainesville, FL 32611

\section{Sample collection}

Four continuous, 10-meter-long sediment cores were collected from two locations at Avery in June 2014 using a modified Livingstone piston corer driven by an electric winch coring tower system mounted on a floating raft (Wright et al., 1984). One-meter-long overlapping Livingstone cores were offset by $50 \mathrm{~cm}$ at each location to ensure complete recovery. Onemeter-long surface cores capturing the sediment-water interface were additionally collected at each of the Livingstone core locations using a modified piston corer. Cores were stored at $4{ }^{\circ} \mathrm{C}$ at the Indiana University-Purdue University, Indianapolis (IUPUI) Paleoclimatology and Sedimentology Laboratory prior to analysis. A composite sediment core measuring $995 \mathrm{~cm}$ was constructed by matching distinct stratigraphic units and sedimentological measurements (magnetic susceptibility, total organic matter, and geochemistry from X-ray fluorescence) from the A-14 coring location. The composite core penetrated to $10.0 \mathrm{~m}$ depth, but the lowest $5 \mathrm{~cm}$ were lost during the coring process because they were composed of coarse sand and gravel, which is difficult to retain with a modified Livingstone corer. Similarities in the physical and visual properties of cores from the two locations (magnetic susceptibility, stratigraphy) indicate consistent depositional patterns at both sites. Therefore, the A-14 composite core was chosen for detailed analysis since it was closest to the Kincaid Archaeological site.

\section{Avery Lake core stratigraphy}

The $995 \mathrm{~cm}$ composite Avery core was visually divided into a basal section between 995 and 972 and an upper section above $972 \mathrm{~cm}$. The basal section from 995 to $988 \mathrm{~cm}$ was composed of medium to coarse sand and gravel, which is consistent with the composition of modern and paleo Ohio River channel deposits (Alexander and Prior, 1971). From 988 to 972 $\mathrm{cm}$, there were alternating layers of sandy silts and sand with abundant charcoal and macro organics. At $972 \mathrm{~cm}$, there was an abrupt transition to massive, tan-to-buff colored, fine-grained sediments that persisted to the top of the core (weak banding occurs above $400 \mathrm{~cm}$ ), consistent with lacustrine swale deposits on the Black Bottom (Alexander and Prior, 1971).

\section{Age control}

Age control for the Avery record was established by accelerator mass spectrometry (AMS) radiocarbon $\left({ }^{14} \mathrm{C}\right.$ ) analysis of 12 samples at the University of California, Irvine (UCI), Keck AMS Laboratory (Table 1). Charcoal and macroscopic terrestrial organic material $>63 \mu \mathrm{m}$ was picked from a wet sieve after a brief disaggregation in a $7 \%$ hydrogen peroxide solution. 
Samples were physically cleaned and chemically pretreated following acid-base-acid protocols (Abbott and Stafford, 1996; Santos, 2011). Radiocarbon ages were calibrated to calendar years before present (cal yr B.P.; present $=1950$ of the Common Era) using the intcal 13 calibration curve (Reimer et al., 2013). Unless otherwise noted, dates in the text are referred to as being in the Common Era (CE) or before (BCE) with 1950 cal yr BP equal to $0 \mathrm{CE}$.

All 12 AMS ${ }^{14} \mathrm{C}$ ages were in stratigraphic order, indicating continuous, undisturbed sediment accumulation. An age model for the Avery core was developed using linear interpolation between AMS ${ }^{14} \mathrm{C}$ ages and the Bayesian age modeling software packages Bchron (Fig. S1a; Parnell et al., 2008). The two age models are virtually identical $\left(\mathrm{r}^{2}=0.999, \mathrm{p}<0.001\right.$, $\mathrm{m}=1.0041)$, with the exception that Bchron introduced a subtle variation in the age model between 2300 and 2050 cal yr BP (Fig. S1b). Therefore, while we use the linear age model to plot all data, age model error estimates are provided based on the Bchron age model. The validity of the Avery age models for the upper $\sim 4$ meters, which represents the last $\sim 200$ years, despite few chronological constrains is supported by the agreement between $\mathrm{Pb}$ concentrations in the Avery sediment archive as determined by XRF and historical records of atmospheric lead pollution (Fig. S1c; Graney et al., 1995). Specifically, peak atmospheric $\mathrm{Pb}$ pollution and peak Avery $\mathrm{Pb}$ concentrations both occurred between 1968 and $1970 \mathrm{CE}$.

Table 1 Avery Lake radiocarbon age data.

\begin{tabular}{ccccccccc}
\hline UCI \# & Material & $\begin{array}{c}\text { Composite } \\
\text { Depth } \\
(\mathbf{c m})\end{array}$ & ${ }^{14}$ C Age & $\begin{array}{c}\text { Error } \\
\mathbf{+} /-\end{array}$ & $\begin{array}{c}\text { Median } \\
\text { Probability } \\
\text { cal yr BP }\end{array}$ & $\begin{array}{c}\mathbf{1} \sigma \\
\text { Upper Age }\end{array}$ & $\begin{array}{c}\mathbf{1} \sigma \\
\text { Lower Age }\end{array}$ & $\begin{array}{c}\text { Maximum } \\
\text { Probability }\end{array}$ \\
\hline 145745 & Charcoal & 404 & 135 & 20 & 130 & 72 & 116 & 0.365 \\
145746 & Charcoal & 505 & 315 & 20 & 390 & 375 & 429 & 0.782 \\
145747 & Charcoal & 656.5 & 805 & 25 & 720 & 693 & 730 & 1 \\
145748 & Charcoal & 724.5 & 950 & 20 & 850 & 827 & 864 & 0.564 \\
182487 & Wood & 727 & 1160 & 15 & 1070 & 1054 & 1085 & 0.534 \\
180591 & Charcoal & 731.5 & 1285 & 15 & 1240 & 1239 & 1267 & 0.541 \\
180592 & Charcoal & 742.25 & 1685 & 15 & 1590 & 1578 & 1604 & 0.633 \\
180593 & Charcoal & 774 & 1945 & 15 & 1890 & 1875 & 1900 & 0.807 \\
180589 & Charcoal & 849.5 & 2260 & 15 & 2310 & 2308 & 2335 & 0.746 \\
180590 & Charcoal & 872 & 2425 & 15 & 2430 & 2376 & 2465 & 0.953 \\
180594 & Charcoal & 946 & 2790 & 15 & 2890 & 2859 & 2890 & 0.654 \\
145749 & Charcoal & 972.5 & 2930 & 20 & 3080 & 3091 & 3144 & 0.581 \\
\hline
\end{tabular}



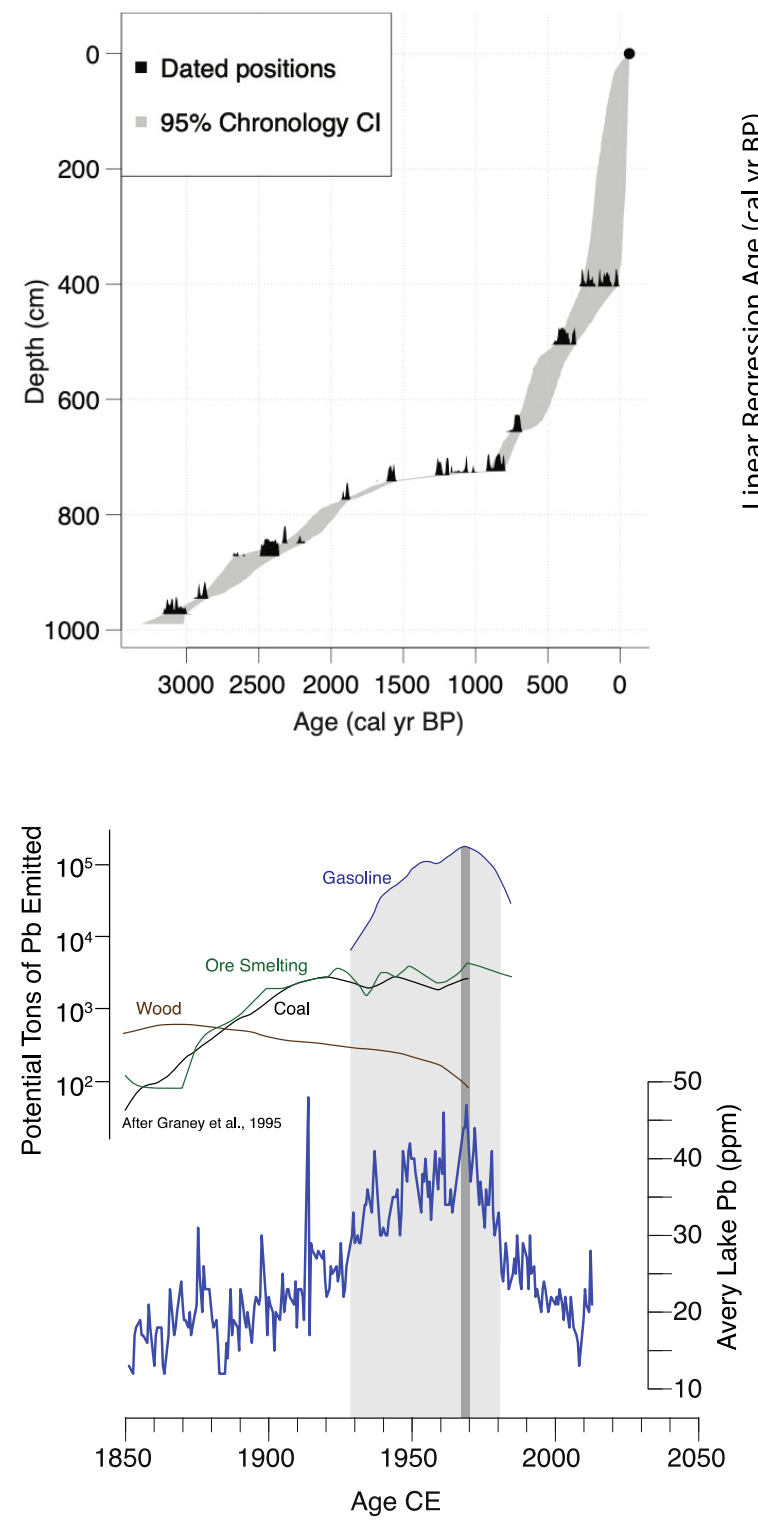

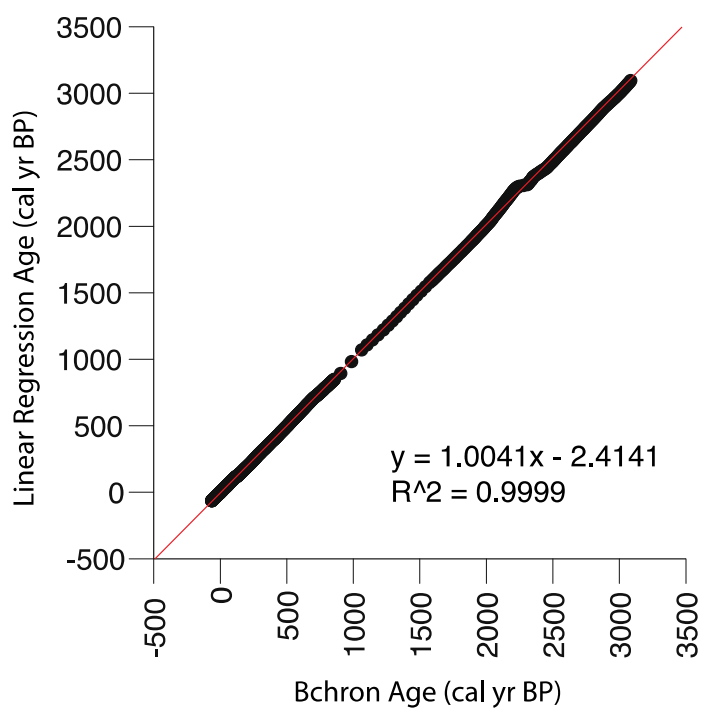

Figure S1 A) Avery Lake age model as derived using Bchron with the 90 to $10 \%$ confidence intervals shown in gray. B) Linear regression of the Bchron and linear regression age models for Avery Lake. C) Comparison of the Avery Lake $\mathrm{Pb}$ record with historical atmospheric lead pollution trends after Graney et al. (1995). The light gray shading indicates the broad peak in $\mathrm{Pb}$ emissions. The drak gray shading indicates maximum historical $\mathrm{Pb}$ emissions between 1968 and 1970, which exactly match peak $\mathrm{Pb}$ in the Avery Lake record.

\section{Organic carbon and total nitrogen elemental abundances and isotopic composition}

The elemental abundances and isotopic composition of organic carbon $\left(\mathrm{C}_{\text {org }} \& \delta^{13} \mathrm{C}_{\text {org }}\right)$ and total nitrogen $\left(\mathrm{N} \& \delta^{15} \mathrm{~N}\right)$ were determined for 150 samples $(\sim 6 \mathrm{~cm}$ resolution) at IUPUI (combustion with a Costech Analytical elemental analyzer coupled by continuous flow to a Thermo Delta V Plus isotope ratio mass spectrometer; IRMS) and Idaho State University (combustion with a Costech ECS 4010 elemental analyzer interfaced to a Thermo Delta V Advantage continuous flow IRMS). Approximately $10 \mathrm{mg}$ of unacidified freeze-dried sample was weighed into tin capsules for isotopic analysis. The sample data are expressed in delta notation in units of per mil (\%) normalized to reference materials (USGS 40, RM 8704, RM $1577 \mathrm{c}$ ). Analytical precision was better than $\pm 0.2 \%$ for both $\delta^{13} \mathrm{C}$ and $\delta^{15} \mathrm{~N}$ and $< \pm 0.5 \%$ of the sample value for $\% \mathrm{~N}$ and $\% \mathrm{C}$. The elemental standard acetanilide $(\mathrm{C}=71.09 \%$, and $\mathrm{N}=$ 
$10.36 \%$ ) was used to correct elemental abundances based on the peak area response of the TCD detector.

\section{Pollen}

Pollen abundances were analyzed for 28 samples $\left(1-\mathrm{cm}^{3}\right.$ of sediment each) collected at variable depth intervals ranging between 2 and $30 \mathrm{~cm}$ in order to focus on temporal areas of interest. Pollen was isolated from the sediment using standard techniques (Faegri \& Iverson, 1989 ) and mounted in silicon oil. Each sample was examined under a light microscope at 400X and a minimum of 300 terrestrial pollen grains (including Cyperaceae) were identified and counted in each sample, to the finest taxonomic resolution possible (family-level or genus-level). Raw pollen counts were then converted to percentages based on the total terrestrial pollen sum.

\section{X-ray fluorescence geochemistry}

Geochemical analyses of lacustrine sediments are routinely made using X-ray fluorescence techniques (XRF; Boyle, 2000; Mejía-Piña et al., 2016). XRF measurements were made on the Avery sediments using a handheld Olympus Innov-X Delta Pro (DPO-6000-C) Xray fluorescence analyzer. Titanium $(\mathrm{Ti})$, zirconium $(\mathrm{Zr})$, and lead $(\mathrm{Pb})$ measured using two energy beams, each with a measurement time of 30 seconds. Beam one had an energy of $40 \mathrm{Kv}$ and beam two had an energy of $10 \mathrm{Kv}$. Results were converted from counts per second to percent (\%) abundance using the system's proprietary software and an Olympus calibration standard.

$\mathrm{Pb}$ pollution endmembers used in the two end-member mixing model

Table 1 Endmember values

\begin{tabular}{lrr}
\hline & ${ }^{206} \mathrm{~Pb} /{ }^{204} \mathrm{~Pb}$ & $\mathrm{~Pb} \mathrm{ppm}$ \\
\hline Endmember A & 19.250 & 11.8 \\
$\begin{array}{l}\text { Avery Lake } \\
\text { Sediments }\end{array}$ & & \\
$\begin{array}{l}\text { Endmember B } \\
\text { Galena }\end{array}$ & 21.1996 & 866000 \\
\hline
\end{tabular}

Pb pollution calculations using XRF Data

Anthropogenic $\mathrm{Pb}$ pollution was independently determined using the XRF Pb concentration data in order to 1) assess the $\mathrm{Pb}$ isotope-based Mississippian period pollution estimate and 2) provide estimates of $\mathrm{Pb}$ pollution during the Baumer phase, which had no $\mathrm{Pb}$ isotopic excursion. An average background $\mathrm{Pb}$ concentration of $10 \mathrm{ppm}$ was first subtracted from the raw $\mathrm{Pb}$ values during the Baumer (300 to $15 \mathrm{BCE}$ ) and Mississippian (1150 to $1400 \mathrm{CE}$ ) periods. The flux of excess $\mathrm{Pb}\left(\mathrm{Pb}^{*} \mu \mathrm{g} / \mathrm{cm}^{2} / \mathrm{yr}\right)$ was then calculated by multiplying $\mathrm{Pb} *(\mu \mathrm{g} / \mathrm{g})$ concentrations by the dry sediment bulk density $\left(\mathrm{g} / \mathrm{cm}^{3}\right)$ and the sedimentation rate $(\mathrm{cm} / \mathrm{yr})$. This flux was then multiplied by the area of Avery Lake $\left(\mathrm{cm}^{2}\right)$ and the number of years between each measurement to determine the amount of $\mathrm{Pb}^{*}(\mu \mathrm{g})$ deposited over the Avery Lake basin. This value was then summed for the time period of interest and converted to metric tons of $\mathrm{Pb}^{*}$ to determine the total $\mathrm{Pb}^{*}$ deposited in Avery Lake during the Baumer and Mississippian periods. 


\section{References}

Abbott, M. B., and Stafford, T. W., 1996, Radiocarbon geochemistry of modern and ancient Arctic lake systems, Baffin Island, Canada: Quaternary Research, v. 45, p. 300-311.

Alexander, C. S., and Prior, J. C., 1971, Holocene sedimentation rates in overbank deposits in the Black Bottom of the lower Ohio River, southern Illinois: American Journal of Science, v. 270, no. 5, p. 361-372.

Boyle, J. F., 2000, Rapid elemental analysis of sediment samples by isotope source XRF: Journal of Paleolimnology, v. 23, no. 2, p. 213-221.

Graney, J., Halliday, A., Keeler, G., Nriagu, J., Robbins, J., and Norton, S., 1995, Isotopic record of lead pollution in lake sediments from the northeastern United States: Geochimica et Cosmochimica Acta, v. 59, no. 9, p. 1715-1728.

Mejía-Piña, K. G., Huerta-Diaz, M. A., and González-Yajimovich, O., 2016, Calibration of handheld X-ray fluorescence (XRF) equipment for optimum determination of elemental concentrations in sediment samples: Talanta, v. 161, p. 359-367.

Parnell, A. C., Haslett, J., Allen, J. R., Buck, C. E., and Huntley, B., 2008, A flexible approach to assessing synchroneity of past events using Bayesian reconstructions of sedimentation history: Quaternary Science Reviews, v. 27, no. 19-20, p. 1872-1885.

Reimer, P. J., Bard, E., Bayliss, A., Beck, J. W., Blackwell, P. G., Ramsey, C. B., Buck, C. E., Cheng, H., Edwards, R. L., and Friedrich, M., 2013, IntCal13 and Marine13 radiocarbon age calibration curves 0-50,000 years cal BP: Radiocarbon, v. 55, no. 4, p. 1869-1887.

Santos, G., 2011, Acid/Base/Acid (ABA) Sample Pretreatment, in Facility, U. o. C. K. C. C. A., ed., University of California Keck Carbon Cycle AMS Facility.

Wright, H. E., Mann, D. H., and Glaser, P. H., 1984, Piston corers for peat and lake sediments: Ecology, v. 65, p. 657-659. 